Altermann, E., Russell, W. M., Azcarate-Peril, M. A. \& other authors (2005). Complete genome sequence of the probiotic lactic acid bacterium Lactobacillus acidophilus NCFM. Proc Natl Acad Sci U S A 102, 3906-3912.

Boekhorst, J., Siezen, R. J., Zwahlen, M. C. \& other authors (2004). The complete genomes of Lactobacillus plantarum and Lactobacillus johnsonii reveal extensive differences in chromosome organization and gene content. Microbiology 150, 3601-3611.

Bolotin, A., Wincker, P., Mauger, S., Jaillon, O., Malarme, K., Weissenbach, J., Ehrlich, S. D. \& Sorokin, A. (2001). The complete genome sequence of the lactic acid bacterium

Lactococcus lactis ssp. lactis IL1403. Genome Res 11, 731-753.

Bolotin, A., Quinquis, B., Renault, P. \& 20 other authors (2004). Complete sequence and comparative genome analysis of the dairy bacterium Streptococcus thermophilus. Nat Biotechnol 22, 1554-1558.

Francke, C., Siezen, R. J. \& Teusink, B. (2005) Reconstructing the metabolic network of a bacterium from its genome. Trends Microbiol 13, 550-558.

Hols, P., Hancy, F., Fontaine, L. \& 11 other authors (2005). New insights in the molecular biology and physiology of Streptococcus thermophilus revealed by comparative genomics. FEMS Microbiol Rev 29, 435-463.

Klaenhammer, T., Altermann, E., Arigoni, F. \& 21 other authors (2002). Discovering lactic acid bacteria by genomics. Antonie van Leeuwenhoek 82, 29-58.

Klaenhammer, T. R., Barrangou, R., Buck, B. L. Azcarate-Peril, M. A. \& Altermann, E. (2005).

Genomic features of lactic acid bacteria effecting bioprocessing and health. FEMS Microbiol Rev 29, 393-409.

Kleerebezem, M., Boekhorst, J., van Kranenburg, R. \& 16 other authors (2003). Complete genome sequence of Lactobacillus plantarum WCFS1. Proc Natl Acad Sci U S A 100, 1990-1995.

Klijn, A., Mercenier, A. \& Arigoni, F. (2005). Lessons from the genomes of bifidobacteria. FEMS Microbiol Rev 29, 491-509.

Molenaar, D., Bringel, F., Schuren, F. H., de Vos, W. M., Siezen, R. J. \& Kleerebezem, M. (2005). Exploring Lactobacillus plantarum genome diversity by using microarrays. J Bacteriol 187, 6119-6127.

Pedersen, M. B., Iversen, S. L., Sorensen, K. I. \& Johansen, E. (2005). The long and winding road from the research laboratory to industrial applications of lactic acid bacteria. FEMS Microbiol Rev 29, 611-624.

Pridmore, R. D., Berger, B., Desiere, F. \& 12 other authors (2004). The genome sequence of the probiotic intestinal bacterium Lactobacillus johnsonii NCC 533. Proc Natl Acad Sci U S A 101, 2512-2517.
Saxelin, M., Tynkkynen, S., Mattila-Sandholm, T. \& de Vos, W. M. (2005). Probiotic and other functional microbes: from markets to mechanisms. Curr Opin Biotechnol 16, 204-211.

Schell, M. A., Karmirantzou, M., Snel, B. \& 9 other authors (2002). The genome sequence of Bifidobacterium longum reflects its adaptation to the human gastrointestinal tract. Proc Natl Acad Sci U S A 99, 14422-14427.

Siezen, R. J., van Enckevort, F. H., Kleerebezem, M. \& Teusink, B. (2004). Genome data mining of lactic acid bacteria: the impact of bioinformatics. Curr Opin Biotechnol 15, 105-115.

Siezen, R. J., Renckens, B., van Swam, I., Peters, S., van Kranenburg, R., Kleerebezem, M. \& de Vos, W. M. (2005). Complete sequence of four plasmids of Lactococcus lactis subsp. cremoris SK11 reveals extensive adaptation to the dairy environment. Appl Environ Microbiol (in press).

Smid, E. J., Molenaar, D., Hugenholtz, J., de Vos, W. M. \& Teusink, B. (2005a).

Functional ingredient production: application of global metabolic models. Curr Opin Biotechnol 16, 190-197.

Smid, E. J., van Enckevort, F. J., Wegkamp, A., Boekhorst, J., Molenaar, D., Hugenholtz, J., Siezen, R. J. \& Teusink, B. (2005b). Metabolic models for rational improvement of lactic acid bacteria as cell factories. J Appl Microbiol 98, 1326-1331.

Teusink, B., van Enckevort, F. H. J., Francke, C., Wiersma, A., Wegkamp, A., Smid, E. J. \& Siezen, R. J. (2005). In silico reconstruction of the metabolic pathways of Lactobacillus plantarum: comparing predictions of nutrient requirements with those from growth experiments. Appl Environ Microbiol 71, 7253-7262.

Vaughan, E. E., Heilig, H. G., Ben-Amor, K. \& de Vos, W. M. (2005). Diversity, vitality and activities of intestinal lactic acid bacteria and bifidobacteria assessed by molecular approaches. FEMS Microbiol Rev 29, 477-490.

\section{DOI 10.1099/mic.0.28557-0}

\section{Balancing the loss and acquisition of pathogenic traits in food-associated bacteria}

The recent description and comparative genome analysis of the lactic acid bacterium Streptococcus thermophilus (Bolotin et al., 2004) provided insights into adaptive evolutionary mechanisms that led to the assembly of a 'generally recognized as safe' (GRAS) species, starting from closely related deadly human pathogens such as Streptococcus pneumoniae, Streptococcus pyogenes and Streptococcus agalactiae.
Bolotin et al. (2004) argued that the species $S$. thermophilus evolved from close phylogenetically related pathogenic streptococci through loss-of-function events. The regressive evolution of S. thermophilus was supported by the finding of an inactive vestige of pathogenesis-related genes ( $10 \%$ of the total sequence), counterbalanced by the acquisition of relevant traits, like lactose utilization, that have allowed the assembly of a new genome organization suitable for the colonization of the dairy niche.

Surprisingly, in the $S$. thermophilus genome analysis, Bolotin et al. (2004) made no reference to the urease gene cluster that accounts for $0.4 \%$ of the total coding sequence and $0.6 \%$ of the total coding sequence belonging to known functional categories. This urease gene cluster, composed of eight genes organized in an operon (Mora et al., 2004), has been found in all $S$. thermophilus strains characterized until now, including natural ureasenegative mutants that, however, have only been isolated with relatively low frequency (Monnet et al., 2004). Since the close pathogenic streptococci considered by Bolotin et al. (2004) do not carry ureolytic determinants, we could postulate that the urease gene cluster in $S$. thermophilus could be a function complementation, probably derived from other bacterial pathogens and fixed on a genomic backbone ancestrally regressed from pathogenic streptococci.

The urease operon, which plays an important technological role in dairy fermentation processes (Mora et al., 2004; Monnet et al., 2004), is often associated with pathogenic bacteria (Mobley et al., 1995; Burne \& Chen, 2000). In fact ureolytic activity has a key role in pathogenesis elicited by bacteria like Clostridium perfringens, Helicobacter pylori, Klebsiella pneumoniae, Proteus mirabilis, Salmonella sp., Staphylococcus saprophyticus, Ureoplasma urealyticum and Yersinia enterocolitica (Mobley et al., 1995; Burne \& Chen, 2000), and such activity has been reported in diseases like urolithiasis, pyelonephritis, ammonia encephalopathy, hepatic encephalopathy, hepatic coma and gastro-duodenal infections (Mobley et al., 1995).

The role of urease is primarily linked to nitrogen assimilation. Ammonium, 
released from the urea present in the secretions of major and minor exocrine glands (1-10 $\mathrm{mM}$ in saliva), provides a nitrogen source for bacteria that colonize the human body, as has been demonstrated for the oral bacteria Streptococcus salivarius (Chen et al., 2000) and Actinomyces naeslundii (Morou-Bermudez \& Burne, 2000). Moreover, the release of alkaline equivalents, mediated by urease, is a major cause of damage to host tissues, a key factor in pathogen persistence (Burne \& Chen, 2000), and can even increase pathogen fitness by counteracting the environmental acidity as observed for Helicobacter pylori in the human stomach.

In the light of these considerations, the maintenance of urease determinants within the $S$. thermophilus genome is certainly dependent on how they contribute to the fitness of the organism in its environment. From an ecological perspective, the availability of an enzyme such as urease could, apart from offering its host the previously mentioned advantages, also positively affect the association between $S$. thermophilus and Lactobacillus delbrueckii subsp. bulgaricus, or that with other lactic acid bacteria in milk, providing ammonium and carbon dioxide from the hydrolysis of milk urea (3-6 mM) and buffering the generated acidity. In $S$. thermophilus it has been recently shown that one of the functions of urease is to supply ammonia for the synthesis of glutamine (Monnet et al., 2005).

Among the 59 recognized species of the genus Streptococcus, the urease operon is restricted to S. alactolyticus, S. hyontestinalis, S. salivarius, S. thermophilus and S. vestibularis. Structural S. thermophilus urease genes show a greater than $96 \%$ identity with the close oral bacterium S. salivarius (Mora et al., 2004), an opportunistic pathogen rather than a GRAS bacterium. S. salivarius has been associated with dental caries, infective endocarditis and meningitis and is classified in the Risk Group 2 according to the EU directive 90/ 679/EEC (German definition). Like $S$. thermophilus, S. salivarius is exposed to milk in the mouth during nursing and shares with $S$. thermophilus not only urease but also another relevant metabolic trait, the specific symporter of lactose. This lactose uptake system, which has $95 \%$ DNA/DNA identity between the two species, is structurally different from the lactose uptake genes of all the other lactic acid bacteria (Vaillancourt et al., 2002).

Other virulence-related genes clusters are still present and functional in the $S$. thermophilus genome. The genes involved in the synthesis of the polysaccharide capsule that surrounds pathogenic streptococci are maintained in the S. thermophilus genome but, unlikely to be considered pathogenic traits, they contribute to the production of external polysaccharides that confer the desirable texture of yogurt (Tettelin, 2004). Also, the genes encoding the oligopeptide transport system (AmiA oligopeptide-binding proteins) resemble those of $S$. pneumoniae on the basis of both structural organization and overlapping specificities and are differently organized compared with those of Lactococcus lactis (Opp system), another GRAS dairy lactic acid bacterium. Nevertheless, on the basis of substrate specificity the oligopeptide system of S. thermophilus resembles that of L. lactis, showing a broad specificity of peptide transport that renders these lactic acid bacteria species well adapted to their natural habitat, milk (Juille et al., 2005).

A conclusion we would like to emphasize is that a gene or a cluster of genes, and the related products, which have been shown to be involved in virulence mechanisms may change their role whilst still retaining their catalytic function (i.e. for urease, the hydrolysis of urea), according to the environmental 'choice' made by the host organism during speciation.

We could therefore postulate that beneficial organisms, even though regressed from pathogens, could still take advantage of characteristics that play an important role in controlling pathogenesis. Hence, the presence of traits related to pathogens, like urease in the GRAS S. thermophilus, indicates that the positive, or negative, value of a bacterium for human beings derives from the proper assembly of suitable genetic loci (linked or not to pathogenesis) driven by environmental constraints.

In the light of such a consideration, the GRAS status of a micro-organism cannot be definitely predicted by a standard comparative genome analysis looking for the presence or absence of genes whose virulence-related function has been demonstrated for bacteria with a different environmental background. Likewise, strains belonging to bacterial taxa considered to be potentially pathogenic for humans may actually be not, if they are members of a defined subpopulation adapted to an environmental niche other than the human body, like animal milk and milk-derived products.

\section{Mora, ${ }^{1}$ C. Monnet ${ }^{2}$ and D. Daffonchio ${ }^{1}$}

${ }^{1}$ Department of Food Science and Microbiology, University of Milan, via Celoria 2, 20133 Milan, Italy

2Unité Mixte de Recherche Génie et Microbiologie des Procédés Alimentaires, Institut National de la Recherche Agronomique, 78850 Thiverval-Grignon, France

Correspondence: Diego Mora (diego.mora@unimi.it)

Bolotin, A., Quinquis, B., Renault, P. \& 20 other authors (2004). Complete sequence and comparative genome analysis of the dairy bacterium Streptococcus thermophilus. Nature Biotechnol 22, 1554-1558.

Burne, R. A. \& Chen, Y. M. (2000). Bacterial ureases in infectious diseases. Microb Infect 2, 533-542.

Chen, Y. M., Weaver, C. A. \& Burne, R. A. (2000). Dual function of Streptococcus salivarius urease. J Bacteriol 182, 4667-4669.

Juille, O., Le Bars, D. \& Juillard, V. (2005). The specificity of oligopeptide transport by Streptococcus thermophilus resembles that of Lactococcus lactis and not that of pathogenic streptococci. Microbiology 151, 1987-1994.

Mobley, H. L. T., Island, M. D. \& Hausinger, R. P. (1995). Molecular biology of ureases. Microbiol Rev 59, 451-490.

Monnet, C., Pernoud, S., Sepulchre, A., Fremaux, C. \& Corrieu, G. (2004). Selection and properties of Streptococcus thermophilus mutants deficient in urease. J Dairy Sci 87, 1634-1640.

Monnet, C., Mora, D. \& Corrieu, G. (2005). Glutamine synthesis is essential for growth of Streptococcus thermophilus in milk and is linked to urea catabolism. Appl Environ Microbiol 71, 3376-3378.

Mora, D., Maguin, E., Masiero, M., Parini, C., Ricci, G., Manichini, P. L. \& Daffonchio, D.

(2004). Characterization of urease genes cluster of Streptococcus thermophilus. J Appl Microbiol 96, 209-219. 
Morou-Bermudez, E. \& Burne, R. A. (2000). Analysis of urease expression in Actinomyces naeslundii WVU45. Infect Immun 68, 6670-6676. Tettelin, H. (2004). Streptococcal genomes provide food for thought. Nat Biotechnol 22 1523-1524.
Vaillancourt, K., Moineau, S., Frenette, M., Lessard, C. \& Vadeboncoeur, C. (2002).

Galactose and lactose genes from the galactosepositive bacterium Streptococcus salivarius and the phylogenetically related galactose-negative bacterium Streptococcus thermophilus: organization, sequence, transcription, and activity of the gal gene products. J Bacteriol 184, 785-793.

DOI 10.1099/mic.0.28513-0 